\title{
Green Construction in India: Gaining a Deeper Understanding
}

\author{
Mohammed Arif, Ph.D. \\ Senior Lecturer, School of Built Environment, Univ. of Salford, Maxwell \\ Building, The Crescent, Greater Manchester, UK M5 4WT. E-mail: \\ m.arif@salford.ac.uk
}

\section{Charles Egbu}

Professor, School of Built Environment, Univ. of Salford, Maxwell Building, The Crescent, Greater Manchester, UK M5 4WT. E-mail: c.o.egbu@salford.ac.uk

\section{Abid Haleem}

Professor, Dept. of Mechanical Engineering, College of Engineering and Technology, Jamia Millia Islamia, New Delhi, India 110025. E-mail: haleem.abid@gmail.com

\section{John Ebohon, Ph.D.}

Reader, Energy Sustainability and Development, De Montfort Univ. in Leicester, The Gateway, Leicester, UK LE1 9BH. E-mail: ebohon@ dmu.ac.uk

\section{Malik M. A. Khalfan, Ph.D.}

Senior Research Fellow, Salford Centre for Research and Innovation (SCRI), Univ. of Salford, Maxwell Building, The Crescent, Greater Manchester, UK M5 4WT. E-mail: M.M.A.Khalfan@Salford.ac.uk

\section{Overview}

Environmental concerns have moved from being a fringe issue in any project to main agenda items at senior executive meetings (Walton et al. 1998). Massive construction activity is taking place globally to accommodate the migration of world population to urban areas, a proportion that is expected to reach $60 \%$ by the year 2030 (Syal et al. 2006). In recent years India has seen major economic growth, and with this growth, construction activities have gone up significantly. In India the current annual investment in construction is around $\$ 70$ billion, with an identified need for an additional $\$ 50$ billion and a projected annual growth rate of $15 \%$. It is estimated that supporting infrastructure will need an investment of around $\$ 163$ billion over the next 10 years (Syal et al. 2006). With a shortage of 41 million housing units to accommodate the existing population (Tiwari 2001), construction activities of all types are taking place at a rapid pace. However, with increased construction activities comes increased environmental concern.

In developed countries where the benefits of going green are extensively documented and the construction sector is encouraged to go green and promote sustainability, there is a reluctance among companies to commit themselves to go green at the corporate policy level (Ofori 2000). However, it would be interesting to elicit the views of the Indian construction sector on the issue of green construction practices and analyze the challenges that can potentially inhibit the adoption of sustainable practices in a growing economy.

Under the wider umbrella of green issues, several initiatives are under way worldwide. The definition of "green" is quite broad, and a wide spectrum of issues is subsumed under this umbrella. Some of the major issues that fall under the "green" category are sustainability, environment, energy, waste minimization, etc. Although we talk about green all the time, individuals from regulatory bodies, private corporations, government agencies, and final consumers view green from different perspectives and use different sets of variables to choose the path of going green. For every member of the supply chain of any construction or infrastructure project, drivers are different, and hence a view of these drivers for different stakeholders is important to understand how green can be made successful and popular.

With this background in mind, a workshop was organized by academics from the University of Salford, U.K., and Jamia Millia Islamia University, India, in New Delhi in July 2008. The workshop included participants from regulatory bodies, public and private construction companies, academics, and researchers from India. This forum presents the findings of that workshop and identifies future directions of research in the area.

\section{Workshop Objectives and Methodology}

The major objectives of this workshop were to

1. Obtain an overview of green practices in the supply chain in the construction sector in India;

2. Provide an opportunity to capture issues, challenges, success factors, and research issues in green practices throughout the supply chain in the construction sector in India;

3. Provide an avenue for people to engage with a community of organizations and institution within the supply chain; and

4. Share experience and learn from others involved in the process.

To provide further focus, the organizers limited the definition of "green" to practices and issues that were environmentally friendly, energy efficient, and resulted in the minimization of waste. The workshop had 20 attendees who included academics, representatives from regulatory bodies, the public sector, and the private sector. A diverse group like this provided a number of different viewpoints and helped provide a deeper understanding of various aspects of green construction practices in India.

The workshop adopted the following methodology. To achieve objective (1), a survey was administered to all participants in the workshop. Evaluations and results of that aspect of the study are pending publication as part of a different paper. This forum focuses on objectives (2), (3), and (4), which were accomplished through the use of facilitated sessions with specific questions. Prior to conducting these sessions, two presentations were made; one highlighting the implementation of green practices in the construction sector in the U.K., and the other highlighting some cur- 
rent green practices in the construction sector in India. These presentations helped focus the thoughts of the participants for the three areas of environment, energy, and waste minimization.

\section{Facilitated Sessions Overview}

As previously noted, to focus the study, the definition of "green" was limited to practices and techniques that were environmentally friendly, energy efficient, and minimized waste. To further focus the discussions, eight questions were formulated by the facilitators that were representative enough to provide an in-depth understanding of the green issues in the Indian construction industry. These questions were

1. What role can financial incentives play in the uptake of "green philosophy?" (Suggest mechanisms.)

2. What is your view with regard to regulatory and voluntary initiatives on greening of supply chains?

3. How do you achieve a balance between profitability and "greening?"

4. What are key challenges (cultural and practical) associated with going green?

5. Given the current Indian government growth predictions and the current energy and environmental crisis, what do you think is the future of green supply chains in the next 5 years?

6. What key solutions in India are making the greatest difference to greening, and why?

7. What are your views on how awareness and understanding of green supply chains can be improved?

8. What are your views toward voluntary and mandatory assessment and audit of green issues?

The participants were divided into two groups. While forming the groups, it was ensured that members of regulatory bodies, academia, and public as well as private companies were included in both groups. Both groups were given one hour to discuss the five questions assigned to them. The first group was asked to discuss questions $1,2,4,5$, and 6 , and the second group was assigned questions $3,4,6,7$, and 8 for discussion in a parallel session. Each group had a facilitator and a scribe. From each group, one volunteer was chosen who would present the findings to the entire audience after the facilitated brainstorming sessions.

\section{Analysis of Facilitated Sessions}

The first question before one of the groups was the role financial incentives could play in the implementation of green practices, and the group was asked to suggest financial mechanisms. The group felt that to provide financial incentives, the government needs to establish a baseline to objectively evaluate an organization or a project. There is a need for an independent auditing organization and enough trained people to perform such audits. The rewards and penalties need to be quantified, and the possibility of tax breaks by the government to organizations that are more committed to green principles is very important as well. Possible mechanisms that can help in the implementation of green principles are

1. Make the green credentials of an organization its prequalification criteria for submitting a proposal.

2. Develop a best practices database and formulate objective ways of quantifying and incentivizing. The issue of quantifying the impact of greening and the impact of financial incentives on greening initiatives received substantial treatment and consideration by participants. Most felt that it was indeed a crucial aspect of the "greening debate." It was suggested that appropriate benchmarks, baselines, and norms need to be established, and that these need to take a variety of contexts and scenarios into account.

3. Create a government fund to offer soft loans and subsidies to organizations committed to green. The government is to create specific funds: There was the feeling among many participants that the government should make "soft loans" available to encourage the adoption and implementation of appropriate projects/solutions that encourage the "greening philosophy." This would help to target and fund best-practice programs and also act as startup funding for deserving "green" projects.

4. Tax breaks should be provided by the government: Tax breaks were felt to be a way of incentivizing and promoting the greening of construction. However, the participants raised the issue that this would only be successful if the scope of what is to be accommodated within the tax breaks were duly considered and reflected reality as much as possible. This subject was raised due to the complex nature of the "greening" debate and issues.

5. Corporations need to pass on the financial benefits of going green downstream to suppliers and customers.

The second question asked of participants was "What is your view with regards to regulatory and voluntary initiatives on greening of supply chains?" As far as the regulations are concerned, the opinion of the participants were as follows:

1. The audit of the regulations and their stricter imposition to ensure compliance is negligible, despite the fact that every major construction and infrastructure project needs environmental clearance. The participants noted that it was one thing to set regulatory standards associated with "greening," but another thing to implement and follow this through. This demands resources, effective communication and effective planning, monitoring, and control across all levels.

2. Corruption was also highlighted as one of the issues associated with enforcement by government agencies relative to environmental regulations.

3. Participants were of the opinion that to pay for enforcement and audit costs, the permit fee needs to be increased.

4. One other issue that was highlighted was the differences in federal and state laws. Some states have more severe laws than others. Therefore, a more unified regulatory framework is needed between state and federal laws.

For voluntary initiatives, the following major points were discussed:

1. Development of more India-specific standards that organizations can implement themselves;

2. Development of a rating system for "green" organizations that provides an evaluation and certification framework; and

3. Need to do more with school and university curriculums to raise awareness about green issues.

The third question posed to the participants was to identify ways of achieving a balance between profitability and greening. There was a general consensus among all participants that the issues of greening need to be viewed from a long-term perspective. All realized that for profit-making enterprises, especially those who are struggling to survive and remain in business, this is not by any means easy. Initial outlay for addressing and providing green solutions are likely to be high and difficult in the short run; and obtaining value is a slow process. There was also the suggestion that microfinancing could be an option for smaller organiza- 
tions. In this respect, they would need to work closely with bigger organizations with more resources. The group proposed the following steps to help strike a balance between the two:

1. Reduction of waste through a wide array of techniques and practices discussed in the workshop survey questionnaire; and

2. Promoting recycling, remanufacturing, and reuse.

The fourth question was about the key challenges associated with going green. This was one of the two questions posed to both groups, due to its significance. The major challenges highlighted are as follows:

1. The literacy rate is low in general, and specifically about environmental issues.

\section{Cultural deterioration}

a. "We keep the inside of the house clean but we don't think that way for the surrounding." This was one of the statements of one of the participants in the workshop. Participants realized that the concern for any green issue among individuals and corporations is limited to themselves and not about the impact it has on the surrounding. Therefore a fundamental cultural shift is needed to address this issue.

b. Older religious activities involved use of trees, and respect for the environment was part of the culture. Respect for trees and the environment formed part of rituals for several Indian religions. However, people have somehow lost sight of that respect for trees and the environment in their day-to-day practice.

Indeed, it was strongly felt that some of the positive cultures, customs, and inherent practices that have been passed on from generation to generation, which have now been degraded, are among the culprits in embracing and practicing the "green philosophy." There was some sense among the participants to revive some of the old ethos. Participants were reminded of the increasing shift from "collectivism" to "individualism." Similarly, there was a reminder of the increasing move toward consumerism and the increasing rate of discarding technological outputs, whereas among the older generations, some of the items that are easily and freely discarded these days, as waste, would still have their use and place. In addition, many of the participants were of the view that there is also a sign of some resistance to how things were done previously in the old days. There was also a strong view from participants about the way we design and how this has, in a way, contributed to an increase in waste. As an example, many of the participants felt strongly that there was some evidence from practice that there is "overdesign" and "over-specification" in construction. For some, there is a need for "optimal design" to be taught and practiced with increased frequency.

3. Poverty is a major obstacle to implementation of green principles. Quite often people, despite knowing about the savings over the life cycle, are not able to afford the additional upfront costs of implementation. This practice results in buying cheaper goods and services, which tend to be less environmentally friendly.

4. Research and development in greener issues is low, and the technology transfer from other countries that have investigated these issues extensively is slow. More needs to be done in this area.

When the participants were asked to comment on their perception about the future of green in the Indian construction sector, they were very optimistic. Some of the responses are as follows:

1. The future is very bright.

2. One of the participants from a private sector company involved in construction of residential and commercial buildings commented that he has seen a shift in people's willingness to pay. Today, some individuals and organizations are starting to show their willingness to consider paying a premium for a greener building.

3. Government is aware of the difficulties in enforcement and is planning processes and regulations to facilitate effective enforcement.

4. Corporate awareness is increasing toward the greening philosophy. The manifestation of this is increasing. For example, in some new airport buildings, natural lighting is on the increase. Cooling loads are down by two-thirds. There is reduction in costs of air-conditioning; air conditioning is now targeted to the place of need (and not just the entirety of the building or space).

5. Some private sector companies have started looking at the possibility of making the departments dealing with green issues profit centers rather than cost centers.

6. Positive shift in culture: We were reminded that unlike before, plants are now being given as presents on special occasions by family and friends. This also adds positively to the "greening" philosophy.

The participants were, however, quick to point out that although great strides are being made and the future is looking more promising, research and development in India is still relatively low. All the participants agreed that the rate of diffusion of the impact of technology transfer in contributing to the green philosophy for the benefit of the common masses is still relatively low, and this needs to increase.

Both groups were asked about the key developments that are making an impact and increasing the implementation of green in India. The lists of developments compiled by the groups include 1. More government regulations have come up, and government has offered tax breaks and subsidies in some projects.

2. Judicial intervention has also further strengthened the case for green. The participants, indeed, singled out the positive role of the courts in support of the green philosophy as one of the key solutions that was making the greatest difference to greening. One example noted was the use of the CNG in commercial buses in Delhi.

3. International pressure has increased: International protocols and expectations were seen as having positive impacts on the growing awareness, understanding, and implementation of the green principles. In addition, the participants noted that globalization and working with foreign organizations that are strict on compliance and environmental practices are also making a difference.

4. General awareness among the masses has also gone up about environment and energy.

5. Recent high fuel prices have also provided a major boost to green initiatives in India, and people have started looking at the life-cycle cost implications of products and services.

6. With the growing economy, the strain on resources has been immense, and this has resulted in initiatives to analyze the possibility of using alternative sources of energy.

When one of the groups was asked about their views on ways of improving the implementation of "green" practices in construction, the following response was offered.

1. Parameters: Defining parameters and metrics to measure green; 
2. Performance: Measuring and auditing performance of organizations and projects on green issues;

3. Facilitation of improving performance by providing education and training to organizations and their employees;

4. Review of curriculum for incorporating environmental issues at school and college levels; and

5. Incentivizing/taxing by government to encourage going green.

Participants were asked about their views on voluntary and mandatory ways of assessment and audit of green implementation in India. They felt that to encourage voluntary implementation and audit, more open market systems such as carbon credits need to be created that provide an incentive for going green. As far as mandatory ways of assessment and audit are concerned, participants felt that government should not only create regulations, but should also provide some initial mechanism and support to help organizations comply with the new regulations. The participants strongly felt that continuous efforts need to be directed toward improving awareness and understanding of greening. They noted that education and training on this should be targeted at different levels (schools, communities, organizations, and industry). The participants were of the view that government establishments and projects that the governments commission should provide an opportunity to convey the principles of "greening," the point here being that the government should be a champion of the "green principles." In addition, it was gleaned from the discussions involving the participants that reinforcement of the green solutions is important and should be an integral part of the move in the direction of improving awareness and understanding of "green principles."

\section{Concluding Remarks}

This paper has summarized the outcomes of facilitated brainstorming sessions from a workshop organized in New Delhi, India. The findings have highlighted major challenges, drivers, initiatives, and ways of effective implementation as well as enforcement. This overview of green practices in the construction sector in India provides a repository of issues, problems, and opportunities for future researchers in the area.

\section{References}

Ofori, G. (2000). "Greening the construction supply chain in Singapore." European J. Purchasing and Supply Management, 6, 195-206.

Syal, M., Hastak, M., Mullens, M., and Sweaney, A. (2006). "United States-India collaborative research directions in urban housing and supporting infrastructure." J. Archit. Eng., 12(4), 163-167.

Tiwari, P. (2001). "Energy efficiency and building construction in India." Build. Environ., 36, 1127-1135.

Walton, S. V., Handfield, R. B., and Melnyk, S. A. (1998). "The green supply chain: Integrating suppliers into environmental management process." Int. J. Purch. Mater. Manage., Spring, 1-10. 